\title{
Topoisomerase II $\alpha$ Expression in Pituitary Adenomas and Carcinomas: Relationship to Tumor Behavior
}

\author{
Sergio Vidal, Ph.D., Kalman Kovacs, M.D., Ph.D., Eva Horvath, Ph.D., Fabio Rotondo, B.R.T,
} Takao Kuroki, M.D., Ricardo V. Lloyd, M.D., PhD., Bernd W Scheithauer, M.D.

Department of Anatomy, Laboratory of Histology, University of Santiago de Compostela Lugo (SV), Spain; Department of Laboratory Medicine and Pathology, St. Michael's Hospital, University of Toronto (SV, KK, EH, FR), Toronto, Canada; and First Department of Neurosurgery, Toho University, School of Medicine (TK, RVL), Tokyo, Japan; and Department of Pathology and Laboratory Medicine (BWS), Mayo Clinic, Rochester, Minnesota

DNA topoisomerase II $\alpha$ (Topo II $\alpha$ ) is a molecular and immunohistochemical marker that indicates proliferation rate and is the target for several antineoplastic agents. The present immunohistochemical study of a large series of surgically removed pituitary tumors was designed to assess the prognostic significance of Topo II $\alpha$ expression relative to patient age, gender, tumor type and size, invasiveness, metastasis, MIB-1-labeling index and angiogenesis. Changes of Topo II $\alpha$ expression in the tumors treated with bromocriptine and octreotide, a long-acting somatostatin analogue were also investigated. Topo II $\alpha$ immunopositivity was detected only in the nuclei of tumor cells. Gonadotroph adenomas, null cell adenomas, and ACTH-producing adenomas had the lowest Topo II $\alpha$ indices, whereas primary pituitary carcinomas and silent type 3 adenomas presented the highest counts. The statistical study demonstrated no significant correlation between Topo II $\alpha$ expression, patient gender, and vascularity. In contrast, significant negative correlation was found between Topo II $\alpha$ expression and patient age. Topo II $\alpha$ expression was significantly higher in invasive than noninvasive tumors. A tendency to have higher counts was also observed in microadenomas compared with in macroadenomas. Although Topo II $\alpha$ and MIB-1 indices were similar in most tumor types, no significant correla-

Copyright $\odot 2002$ by The United States and Canadian Academy of Pathology, Inc.

VOL. 15, NO. 11, P. 1205, 2002 Printed in the U.S.A.

Date of acceptance: August 7, 2002.

This work was supported in part by a grant from the Ministerio de Ciencia y Tecnología Dirección General de Investigación (BFI2001-3336-CO2-02) and by a generous donation from Mr. and Mrs. Jarislowski and the Lloyd Carr-Harris Foundation. SV was supported by a research grant from Conselleria de Educación (Xunta de Galicia) Spain.

Address reprint requests to: Bernd W. Scheithauer, M.D., Department of Pathology and Laboratory Medicine, Mayo Clinic, 200 First Street, SW, Rochester, MN 55905; e-mail: scheithauer.bernd@mayo.edu; fax: 507-284-1599.

DOI: 10.1097/01.MP.0000036342.73003.55 tion between Topo II $\alpha$ and MIB-1-labeling indices ( $r=.16, P=.09$ ) was found. Only non-functioning adenomas showed positive correlation $(r=.41, P=$ .006) between both proliferation markers. Our results demonstrated a significant decrease in Topo II $\alpha$ index in octreotide-treated, GH-producing adenomas, compared with untreated tumors, but no significant changes were observed in bromocriptinetreated, PRL-producing adenomas. The present study showed no significant advantage of Topo II $\alpha$ over MIB-1 as a prognostic marker; however, Topo II $\alpha$ may provide crucial information regarding selection of adenohypophyseal tumors responsive to antineoplastic therapy, such as invasive pituitary adenomas and pituitary carcinomas, which exhibit a high Topo II $\alpha$ index.

KEY WORDS: Angiogenesis, Cell proliferation, DNA topoisomerase II $\alpha$, Immunohistochemistry, MIB-1, Pituitary neoplasm, Prognosis.

Mod Pathol 2002;15(11):1205-1212

Cell proliferation is controlled by various cell cycle regulators. Changes in pathways regulating the cell cycle are linked to tumorigenesis. Studies have demonstrated that in rapidly proliferating tumor cells, DNA topoisomerase content is higher than in normal cells $(1,2)$. DNA topoisomerases are ubiquitous, indispensable enzymes that control and modify the topological state of DNA in eukaryotic cells. DNA topoisomerases have been divided into two types; Type I induces transient DNA singlestrand breaks and is mainly involved in transcription, whereas Type II, by causing transient breaks and passing a double-strand DNA segment through the break, plays an important role in DNA replication and mitosis $(3,4)$. Type II topoisomerase is the target of several effective anticancer drugs that apparently freeze the enzyme in the act of cutting DNA, the result being the accumulation of double- 
strand DNA breaks that are lethal to the cell. It has been shown that sensitivity to drugs that inhibit DNA topoisomerase II depends upon the level of expression of the DNA topoisomerase II $\alpha$ (Topo II $\alpha$ ) gene encoding an isoform present in target tumor cells (5-7). Topo II $\alpha$ expression and activity is linked to the cell cycle and is associated with proliferation of both normal and neoplastic cells. Topo II $\alpha$, which is synthesized in late Gl or early S phase, is present during G2 and M phases and is subsequently degraded when the cell enters the G1 phase (8). Recent immunohistochemical studies have shown Topo II $\alpha$ to be a reliable marker of cell proliferation in various tumor types, such as carcinomas of the breast and uterine cervix, as well as hematologic, soft tissue, and central nervous system malignancies (9-14). These studies also showed a significant correlation between Topo II $\alpha$ and MIB-1 expression. The latter is a widely used cell proliferation marker, detected by a monoclonal antibody recognizing Ki-67, a protein of unknown function, which is present in actively cycling cells $(15,16)$. MIB-1 labeling is a reliable indicator of proliferative activity in various tumor types, including pituitary tumors. The labeling index MIB-1 is higher in invasive and recurring tumors than in expansively growing and nonrecurring neoplasms (17). Recently, Saeger et al. (18) reported a correlation between Topo II $\alpha$ and MIB-1-labeling indices in nonfunctioning pituitary adenomas and suggested that Topo II $\alpha$ is a useful marker of tumor behavior.

The present immunohistochemical study of a large series of surgically removed pituitary tumors was designed to assess the prognostic significance of Topo II $\alpha$ expression relative to patient age, gender, tumor type and size, invasiveness, metastasis, MIB-1-labeling index, and angiogenesis. We have also investigated the effect of dopamine agonist and long-acting somatostatin analog treatment on Topo II $\alpha$ expression.

\section{MATERIAL AND METHODS}

\section{Material}

The cases studied comprised a series of 164 pituitary tumors selected from the Mayo Clinic Tissue Registry and from the consultation files of three of the authors (BWS, KK, EH). Seventy-five patients were men (mean age, 52.9 y; range, $11-81$ y), and 89 were women (mean age, $45.7 \mathrm{y}$, range, 17-80 y). Essential data, including patient age and sex, tumor size, invasiveness, and metastasis were available in all cases. Each tumor was investigated and classified according to the criteria defined by the World Health Organization (WHO; 19). Specimens included 10 GH-producing adenomas, 37 PRL- producing adenomas, 19 ACTH-producing adenomas (9 Nelson's syndrome, 10 cases Cushing's disease), 10 TSH-producing adenomas, and 61 clinically nonfunctioning adenomas, including 8 silent ACTH cell adenomas of Subtype 1, 13 silent Subtype 3 adenomas, female and male gonadotroph adenomas (10 each), as well as nononcocytic and oncocytic null cell adenomas (10 each). Also studied were 10 bromocriptine-treated, PRL cell adenomas and 10 octreotide-treated, GH-producing adenomas. Lastly, 7 pituitary carcinomas (4 PRL and 3 ACTH producing) were included in the study.

\section{Morphologic Studies}

All specimens were obtained at transsphenoidal surgery, fixed in $10 \%$ buffered formalin, routinely processed, paraffin embedded, and cut at $5 \mu \mathrm{m}$. Each tumor was characterized by hematoxylin and eosin $(\mathrm{H}+\mathrm{E})$, periodic acid-Schiff (periodic acidSchiff), and in some cases the Gordon-Sweet silver method for reticulin fibers. Immunohistochemistry employed the labeled streptavidin-biotin peroxidase complex method, and antibodies to the complete spectrum of pituitary hormones, including growth hormone $(\mathrm{GH})$, prolactin (PRL), adrenocorticotropic hormone (ACTH), luteinizing hormone (LH), follicle-stimulating hormone (FSH), thyrotropic hormone (TSH), and the alpha subunit of glycoprotein hormones. The sources, dilutions, and clonality of the antibodies used, as well as the control methods, have been described elsewhere. Immunostaining was also performed to analyze expression of Ki-67 protein and microvessel density using the monoclonal antibodies MIB-1 to demonstrate nuclei in the cell cycle and CD-34 to localize endothelial cell, respectively. Details of immunohistochemistry, including duration of exposure and control procedures, as well as morphometry quantification, have been described in previous publications $(17,20)$.

Many tumors (119 cases) were also glutaraldehyde fixed, routinely processed, Epon embedded, and examined by transmission electron microscopy.

Topo II $\alpha$ indices were determined immunohistochemically. Staining was performed using a mouse monoclonal antibody recognizing the $\alpha$ isoform of human DNA topoisomerase II (DAKO, Carpinteria, CA). Preliminary titration experiments showed the optimal working dilution to be 1:800. After routine deparaffinization, rehydration, and blocking of endogenous peroxidase activity, sections underwent antigen retrieval by microwaving in $0.1 \mathrm{~mm}$ sodium citrate buffer ( $\mathrm{pH}$ 6.0), as previously described (21). Subsequently treated slides were incubated with the primary antiserum and then exposed to the streptavidin-biotin peroxidase complex. Diaminobenzidine served as the chromogen. Positive con- 
trol slides using nonneoplastic human tonsil were included in each batch. To confirm the specificity of the primary antibody, control tests included substitution of the primary antiserum with phosphatebuffered saline.

Topo II $\alpha$-immunostained sections were examined by computer image analysis (Microimage, Media Cybernetics, Silver Spring, MD); all quantitative evaluations were performed blindly by one of the authors (SV). The Topo II $\alpha$ index was determined based on the number of tumor cell nuclei staining positively for DNA Topo II $\alpha$, divided by the total number of tumor cell nuclei counted. At least 1000 cells were counted in contiguous fields on each slide. Staining was not interpreted in areas of necrosis, fibrosis, or tissue artifact.

Data were tested for statistical significance using the SPSS statistical computer program (SPSS, Inc., Chicago, IL). Because assumptions for a parametric test were not valid (Kolmogorov-Sminov $P<.05$ ), all data were evaluated by Kruskall-Wallis analysis of variance and the Mann-Whitney $U$ test as a multiple-comparison method. The Spearman test was used to assess the statistical significance of the correlation between Topo II $\alpha$ indices, tumor vascularity, patient age, and MIB-1-labeling indices. Differences of $P<.05$ were considered statistically significant.

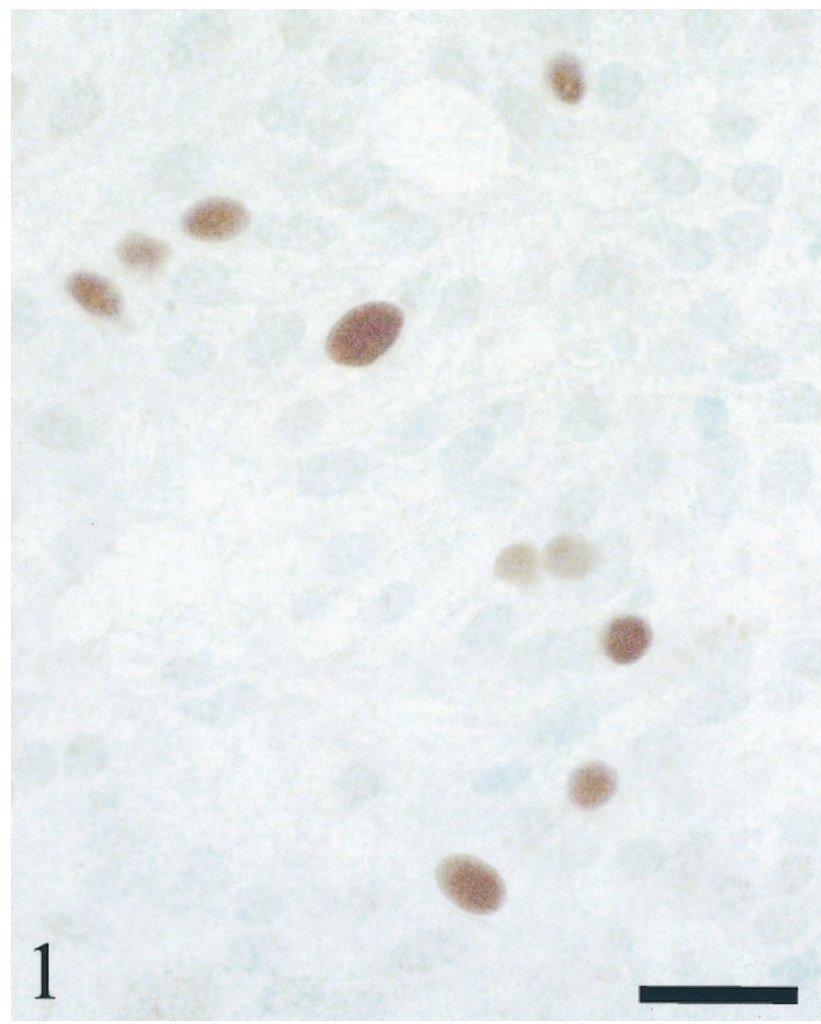

FIGURE 1. Immunostaining for Topo II $\alpha$ in pituitary carcinoma shows numerous positive cells. Bar, $20 \mu \mathrm{m}$.

\section{RESULTS}

Analysis of Topo Il $\alpha$ Immunostaining

Topo II $\alpha$ immunopositivity confined to the nuclei of tumor cells, were easily identified and quantified (Figs. 1 and 2). The range of nuclear immunopositivity over the entire series was 0 to $61.4 \%$ (mean, $4.1 \%)$. Forty of the 164 pituitary tumors $(24 \%)$ were immunonegative, whereas in 36 cases $(22 \%)$, the Topo II $\alpha$ index exceeded the mean value. No Topo II $\alpha$ immunoreactivity was observed in normal adenohypophysial cells in the sections containing nontumorous pituitary tissue.

\section{Relations between Topo II $\alpha$ Index and Clinicopathologic Variables}

A significant negative correlation was found between Topo II $\alpha$ expression and patient age $(r=$ $-0.32, P=.001)$. No significant differences in Topo II $\alpha$ indices were noted in the tumors of male and female patients $(P=.25)$.

Significant differences in Topo II $\alpha$ indices were noted among the various pituitary tumor types (Fig. 3). Gonadotroph adenomas (both subtypes), null cell adenomas (nononcocytic and oncocytic), and ACTH-producing adenomas had the lowest Topo II $\alpha$ indices, whereas primary pituitary carcinomas and silent Type 3 adenomas presented the highest

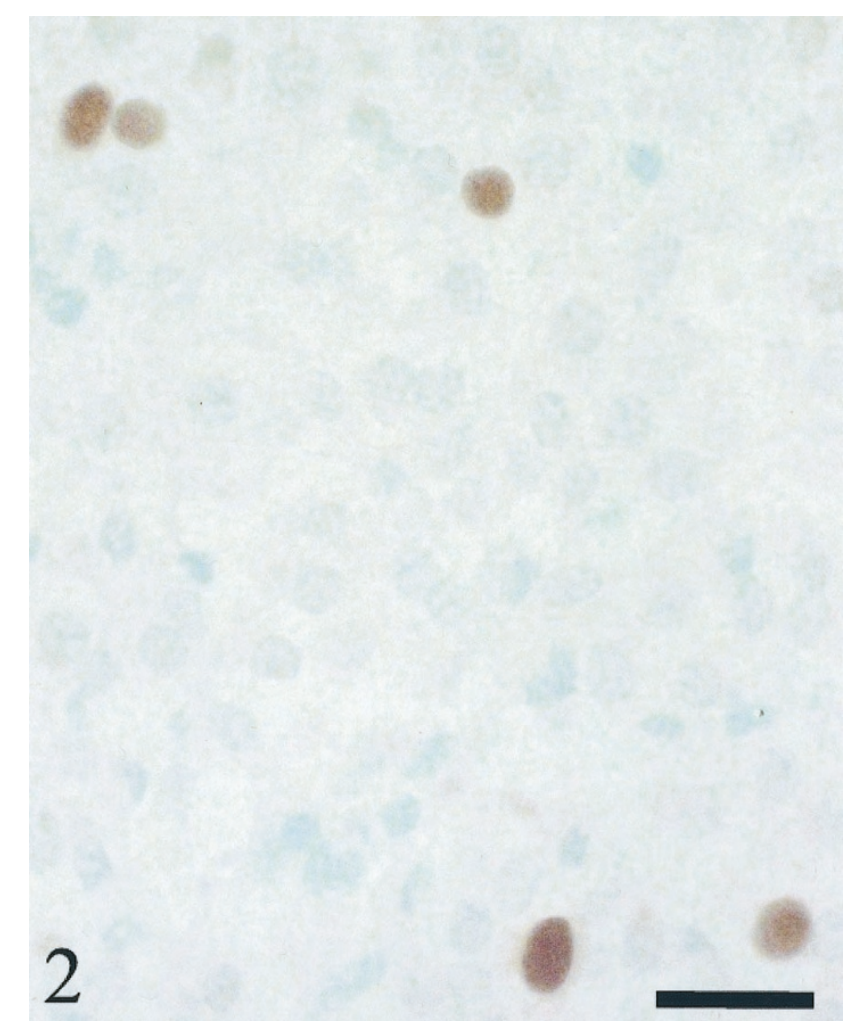

FIGURE 2. Immunohistochemical staining of PRL-producing adenoma for Topo II $\alpha$ showing some positive cells. Bar, $20 \mu \mathrm{m}$. 


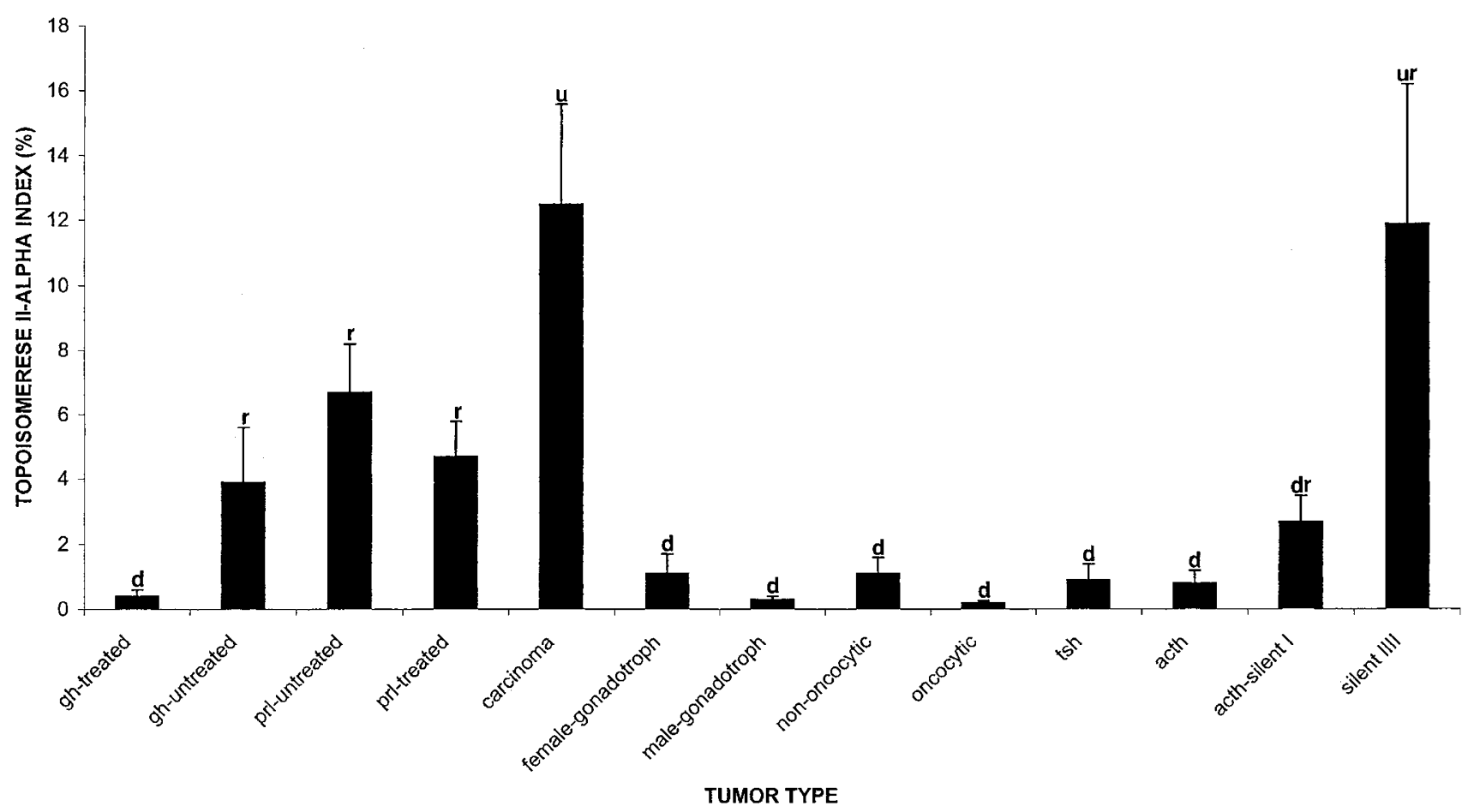

FIGURE 3. Topo II $\alpha$-labeling index in treated and untreated pituitary tumors. The data are expressed as percentage of Topo II $\alpha$-immunopositive cells and represent the mean \pm SEM. Values with no letters in common are significantly different $(P<.05$; statistical analysis with the KruskallWallis analysis of variance and the Mann-Whitney $U$ test).

counts. An intermediate level of Topo II $\alpha$ expression was detected in GH-producing adenomas, PRL-producing adenomas, and ACTH cell adenomas of Silent Subtype 1. Topo II $\alpha$ expression was significantly higher $(P<.05)$ in PRL- and ACTHproducing pituitary carcinomas than in corresponding adenomas.

Significantly higher levels of Topo II $\alpha$ were detected in invasive $(5.9 \pm 1.85 \%)$ than in noninvasive tumors $(2.3 \pm 0.7 \%)$.

No significant differences were demonstrated in the levels of Topo II $\alpha$ immunopositivity between macroadenomas ( $>1 \mathrm{~cm}$ in diameter; $4.4 \pm 0.7 \%$ ) and microadenomas $(7.8 \pm 4.2 \%)$. Nonetheless, a tendency to have higher counts was noted in microadenomas. Thus, in 13 of 30 (44\%) of microadenomas, Topo II $\alpha$ indices exceeded the $4.1 \%$ mean value, whereas only 33 of 134 (25\%) macroadenomas had values $>4.1 \%$. It should also be noted that significantly higher Topo II $\alpha$ indices $(P<.05)$ were observed in invasive macroadenomas $(4.4 \pm 1.3 \%)$ as compared with in noninvasive macroadenomas $(1.7 \pm 0.7 \%)$; and in invasive microadenomas (14.3 $\pm 3.1 \%)$ as compared with in noninvasive microadenomas $(4.7 \pm 1.3 \%)$.

Relationship between Topo II $\alpha$ Index and MIB-1Labeling Index

Nuclear MIB-1 immunostaining detected in tumor cells was highly variable (range, 0 to 25.8; mean, 1.7\%). Considering the series as a whole, the Spearman test showed no significant correlation between Topo II $\alpha$ and MIB-1-labeling indices $(r=$ $.16, P=.09)$. However, strong positive correlation $(r$ $=.41, P=.006)$ was observed when only nonfunctioning adenomas were considered. Although Topo II $\alpha$ and MIB-1 indices were somewhat similar in most tumor types (Fig. 3), the incidence of Topo II $\alpha$ and MIB-1 immunonegative cases differed in each tumor type (Figs. 4 and 5). Our data indicates that in all pituitary tumor types, MIB-1 expression is more frequent than that of Topo II $\alpha$. MIB-1 immunonegative cases were detected only among octreotide-treated, GH-producing adenomas. To varying extents, Topo II $\alpha$ negativity was noted in all tumor types except silent ACTH cell adenomas of Subtype 1 and in Silent Subtype 3 adenomas. It is also of note that although all pituitary carcinomas showed high MIB-1 labeling (MIB-1-labeling index of $>1.7$ ), only $66 \%$ had high Topo II $\alpha$ expression (Topo II $\alpha$ index of $>4.1$ ).

Relationship between Topo II $\alpha$ Index and Microvascular Density

Immunoreactivity for CD34 was easy to quantify in that it was entirely confined to endothelial cells lining the capillaries.

When all types of pituitary tumors were analyzed together, no statistical correlation was found between the Topo II $\alpha$ index and MVD $(P=.42)$. How- 


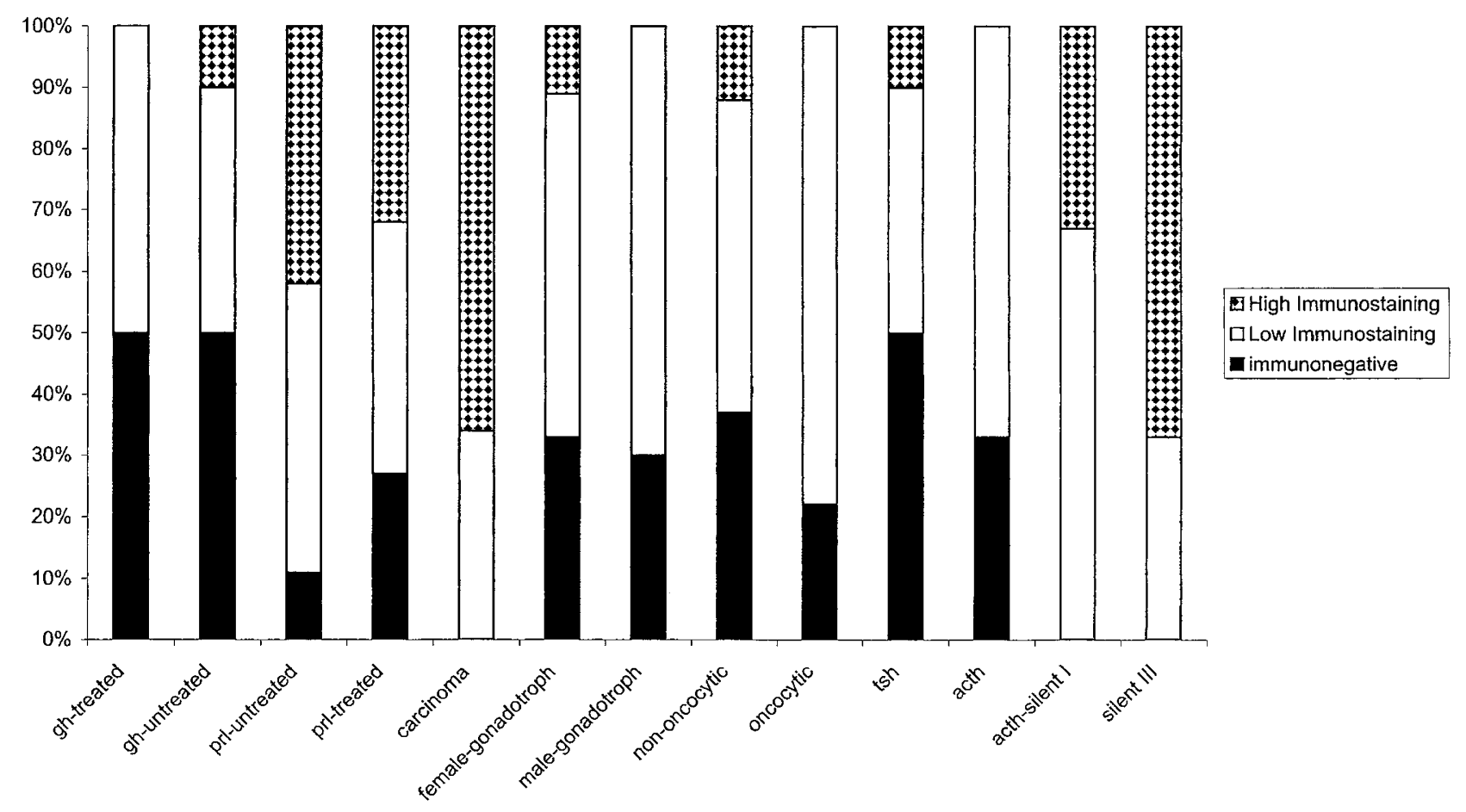

FIGURE 4. Topo II $\alpha$-labeling index in treated and untreated pituitary tumors. Each bar denotes percentage of cases immunonegative (0) and with low $(0$ to $2 \%)$ and high $(>2 \%)$. Topo II $\alpha$ expression in each tumor type.

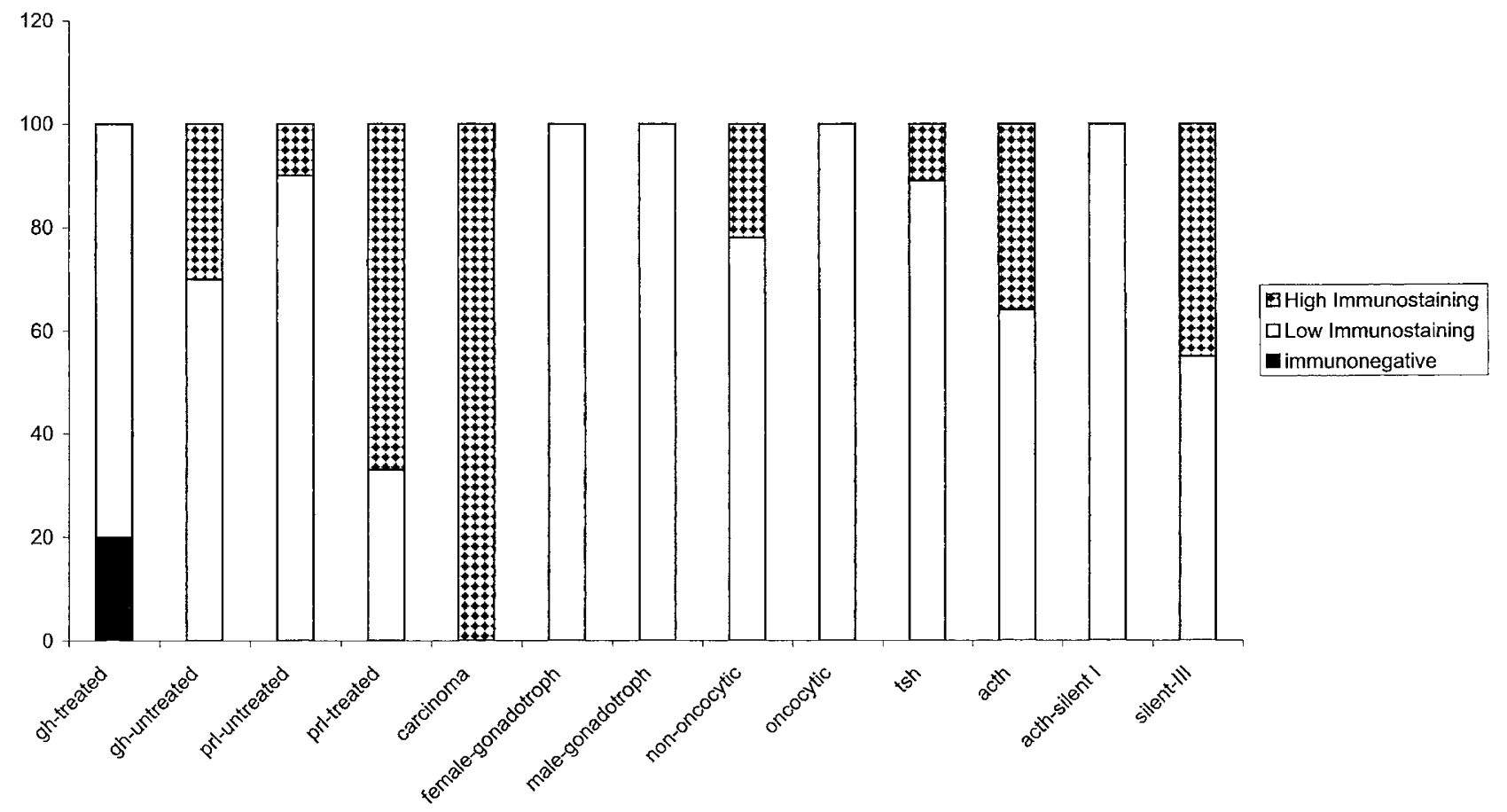

FIGURE 5. MIB-1-labeling index in treated and untreated pituitary tumors. Each bar denotes percentage of cases immunonegative (0) and with low (0 to $2 \%)$ and high ( $>2 \%$ ) MIB-1 expression in each tumor type.

ever, among nonfunctioning adenomas, a negative correlation $(r=-0.34, P=.02)$ was observed between these parameters. A similar negative correlation $(r=-0.32, P=.01)$ was noted between the Topo II $\alpha$ index and MVD in noninvasive tumors.
Topo Il $\alpha$ Index in Bromocriptine- and OctreotideTreated Pituitary Tumors

As shown in Fig. 3, a statistically significant decrease in the Topo II $\alpha$ index was detected in octreotide-treated, GH-producing adenomas as 
compared with those of medically untreated patients. In contrast, although bromocriptine-treated PRL-producing adenomas tended to have lower Topo II $\alpha$ indices than untreated tumors, the differences did not reach statistical significance $(P=.35)$. Significantly reduced MIB-1-labeling indices were noted in both octreotide- and bromocriptinetreated adenomas as compared with untreated tumors $(P<.05)$.

\section{DISCUSSION}

Molecular and immunohistochemical markers have been established as diagnostic and prognostic indicators for a large number of tumors. Studies of various markers, such as proto-oncogenes and tumor suppressor genes, have provided insight into the genetic lesions responsible for neoplastic transformation and support for the notion that genetic alterations also promote tumor development and progression $(22,23)$. For example, the aggressive behavior of some pituitary tumors is related to mutations of c-ras and c-myc proto-oncogenes as well as the tumor suppression gene p53 $(24,25)$.

In addition to proto-oncogenes and tumor suppressor genes, several biomarkers of cell proliferation, such as PCNA (proliferating cell nuclear antigen), Ki-67, BrdUrd (bromodeoxyuridine) p-27, cyclins, and AgNOR (argyrophilic nuclear organization region) have documented abnormalities of cell kinetics associated with tumorigenesis and tumor progression (26-28). Increase in cell proliferation and abnormal distribution of proliferating cells suggest that most human tumors arise from the expansion of a single clone having a selective advantage. With respect to adenohypophysial tumors, it seems intuitive that Ki-67 expression, as detected by the MIB-1 antibody, is a marker not only of proliferative activity but of invasiveness and prognosis as well (17). Indeed, although such tumors generally exhibit a slow growth rate, the prognostic value of cell proliferation markers has been confirmed in different studies showing correlation between increased expression of PCNA, Ki-67, p-27, or cyclins and aggressive tumor behavior $(17,29,30)$. Not surprisingly, study of Topo II $\alpha$ also shows a significant correlation between its over-expression and outcome variables. Thus, Topo II $\alpha$ immunoreactivity is another useful prognostic marker in patients with adenohypophysial tumors. Its higher level of expression in invasive and metastasizing pituitary tumors indicates that enhanced cell proliferation plays a key role in aggressive behavior, particularly in invasion and/or metastasis. Based on significant correlation observed between Topo II $\alpha$ and MIB-1 in various tumors systems (9-14), it has been suggested that these two markers detect the same pro- tein. However, previous studies have demonstrated that the genetic sequence of Ki-67 has no homology to the gene sequence of Topo II $\alpha$ (31). Our study also supports the apparent independence of these two proliferative markers. In accordance, no significant association was observed between Topo II $\alpha$ and MIB-1 reactivities in functioning pituitary adenomas, that is, tumors secreting hormones in excess. Several factors might contribute to the lack of correlation between the expression of these two proliferation markers. For example, Ki-67 expression was detected in all functioning pituitary tumors, whereas Topo II $\alpha$ immunonegative cases were found among the same groups. These differing patterns of immunoreactivity might be explained by the shorter cell cycle time during which Topo II $\alpha$ is expressed (S and G2/M phases), and its rapid degradation in the G1 phase, a time during which Ki-67 is still present $(8,32)$. As reported in ovarian adenocarcinomas and adrenocortical neoplasms, Topo II $\alpha$ immunoreactivity may reflect not only increased cell proliferative activity but also qualitative alterations in and/or dysregulation of Topo II $\alpha$ related to malignant transformation (33). For example, previous in vitro studies using lymphoma showed that Topo II $\alpha$ is expressed in not only the $S$ and G2/M phases but in other phases of the cell cycle as well (34). It was also noted that in some tumor cells, Topo II $\alpha$ has a longer half-life compared with that observed in nontumorous cells (32).

In contrast to functioning pituitary adenomas, clinical symptoms related to nonfunctioning tumors depend on tumor size and pressure effects upon surrounding structures. In such tumors, a significant positive correlation was reported between Topo II $\alpha$ and MIB-1 indices. Our results are in agreement with those of Saeger et al. (18), who studied nonfunctioning adenomas and demonstrated a correlation between Topo II $\alpha$ index and various proliferation markers, such as MIB-1 and cyclin D3.

In general, adenohypophysial tumors are slow growing and remain undetected until endocrinologic alterations and/or neurologic symptoms become manifest. The highly significant negative correlation observed between Topo II $\alpha$ expression and patient age is not surprising because an expanding sellar mass often causes visual disturbances and various degrees of hypopituitarism in older patients (35).

Considering all pituitary tumor types, the present study shows that Topo II $\alpha$ and angiogenesis are independent prognostic indicators. Lack of an association between Topo II $\alpha$ expression and microvascular density is consistent with the results of previous studies, which failed to demonstrate a correlation between proliferation marker expression 
and MVD in pituitary tumors (36). Numerous hypotheses have been proposed to explain the apparent lack of a correlation between angiogenesis and growth of some tumors. It was claimed that microvessel density is more indicative of apoptosis than of cell proliferation (36). It was also suggested that peliosis, a process known to occur in pituitary tumors (37), may interfere with the interpretation of results. Recent studies have also provided evidence that MVD is not fully responsible for proliferation of pituitary adenoma cells (unpublished data).

The present study showed no significant advantage of Topo II $\alpha$ over MIB-1 as a prognostic marker. It is of note, however, that unlike MIB-1, the chemical composition and regulation of Topo II $\alpha$ are understood. Furthermore, Topo II $\alpha$ expression in many human malignancies may provide crucial information regarding the appropriate selection of antineoplastic therapy. Topo II $\alpha$ is the target for a number of antineoplastic agents, including etoposide, mitoxantrone, teniposide, and doxorubicin (38). Chemosensitivity of tumor cells to Topo II $\alpha$ inhibitors depends on the level of expression of Topo II $\alpha$ in target cells, thus suggesting that drugs suppressing Topo II $\alpha$ activity may be used in the treatment of a wide range of adenohypophysial tumors. Specifically, drugs that inhibit Topo II $\alpha$ expression may be of use in treating invasive pituitary adenomas and pituitary carcinomas, both of which exhibit a high Topo II $\alpha$ index.

Acknowledgment: The authors are grateful to the staff of St. Michael's Hospital Health Sciences Library for their contribution in this study.

\section{REFERENCES}

1. Hsiang YH, Wu HY, Liu LF. Proliferation-dependent regulation of DNA topoisomerase II in cultured human cells. Cancer Res 1988;48:3230-5.

2. Giovanella BC, Stehlin JS, Wall ME, Wani MC, Nicholas AW, Liu LF, et al. DNA topoisomerase I-targeted chemotherapy of human colon cancer in xenografts. Science 1989;246: 1046-8.

3. Uemura T, Ohkura H, Adachi Y, Morino K, Shiozaki K, Yanagida M. DNA topoisomerase II is required for condensation and separation of mitotic chromosomes in S. pombe. Cell 1987;50:917-25.

4. Wang JC. DNA topoisomerases. Annu Rev Biochem 1996;65: 635-92.

5. Froelich-Ammon SJ, Osheroff N. Topoisomerase poisons: harnessing the dark side of enzyme mechanism. J Biol Chem 1995;270:21429-32.

6. Mao Y, Yu C, Hsieh TS, Nitiss JL, Liu AA, Wang H, Liu LF. Mutations of human topoisomerase II alpha affecting multidrug resistance and sensitivity. Biochemistry 1999;38: 10793-800.

7. Nitiss JL, Beck WT. Antitopoisomerase drug action and resistance. Eur J Cancer 1996;32A:958-66.
8. Woessner RD, Mattern MR, Mirabelli CK, Johnson RK, Drake FH. Prolifera. Cell Growth Differ 1991;2:209-14.

9. Lynch BJ, Guinee DG Jr, Holden JA. Human DNA topoisomerase II-alpha: a new marker of cell proliferation in invasive breast cancer. Hum Pathol 1997;28:1180-8.

10. Holden JA, Townsend JJ. DNA topoisomerase II-alpha as a proliferation marker in astrocytic neoplasms of the central nervous system: correlation with MIB1 expression and patient survival. Mod Pathol 1999;12:1094-100.

11. Gibbons D, Fogt F, Kasznica J, Holden J, Nikulasson S. Comparison of topoisomerase II alpha and MIB-1 expression in uterine cervical squamous lesions. Mod Pathol 1997;10:40913.

12. Taniguchi $\mathrm{K}$, Wakabayashi $\mathrm{T}$, Yoshida $\mathrm{T}$, Mizuno $\mathrm{M}$, Yoshikawa $\mathrm{K}$, Kikuchi A, et al. Immunohistochemical staining of DNA topoisomerase IIalpha in human gliomas. J Neurosurg 1999;91:477-82.

13. Holden JA, Perkins SL, Snow GW, Kjeldsberg CR. Immunohistochemical staining for DNA topoisomerase II in nonHodgkin's lymphomas. Am J Clin Pathol 1995;104:54-9.

14. Rudolph P, Kellner U, Chassevent A, Collin F, Bonichon F, Parwaresch R, et al. Prognostic relevance of a novel proliferation marker, Ki-S11, for soft-tissue sarcoma. A multivariate study. Am J Pathol 1997;150:1997-2007.

15. Gerdes J, Li L, Schlueter C, Duchrow M, Wohlenberg C, Gerlach C, et al. Immunobiochemical and molecular biologic characterization of the cell proliferation-associated nuclear antigen that is defined by monoclonal antibody Ki-67. Am J Pathol 1991;138:867-73.

16. Schwarting R. Little missed markers and Ki-67. Lab Invest 1993;68:597-9.

17. Thapar K, Kovacs K, Scheithauer BW, Stefaneanu L, Horvath E, Pernicone PJ, et al. Proliferative activity and invasiveness among pituitary adenomas and carcinomas: an analysis using the MIB-1 antibody. Neurosurgery 1996;38:99-106.

18. Saeger W, Schreiber S, Ludecke DK. Cyclins D1 and D3 and topoisomerase II $\alpha$ in inactive pituitary adenomas. Endocr Pathol 2001;12:39-47.

19. Kovacs K, Scheithauer BW, Horvath E, Lloyd RV. The World Health Organization classification of adenohypophysial neoplasms. A proposed five-tier scheme. Cancer 1996;78:502-10.

20. Vidal S, Kovacs K, Horvath E, Scheithauer BW, Kuroki T, Lloyd RV. Microvessel density in pituitary adenomas and carcinomas. Virchows Arch 2001;438:595-602.

21. Vidal S, Roman A, Oliveira MC, De La Cruz LF, Moya L. Simultaneous localization of Pit-1 protein and gonadotropins on the same cell type in the anterior pituitary glands of the rat. Histochem Cell Biol 1998;110:183-8.

22. Shimon I, Melmed S. Genetic basis of endocrine disease: pituitary tumor pathogenesis. J Clin Endocrinol Metab 1997; 82:1675-81.

23. Suhardja A, Kovacs K, Rutka J. Genetic basis of pituitary adenoma invasiveness: a review. J Neurooncol 2001;52:195204.

24. Thapar K, Scheithauer BW, Kovacs K, Pernicone PJ, Laws ER Jr. p53 expression in pituitary adenomas and carcinomas: correlation with invasiveness and tumor growth fractions. Neurosurgery 1996;38:763-70.

25. Boggild MD, Jenkinson S, Pistorello M, Boscaro M, Scanarini M, McTernan P, et al. Molecular genetic studies of sporadic pituitary tumors. J Clin Endocrinol Metab 1994;78:387-92.

26. Brooks DJ, Garewal HS. Measures of tumor proliferative activity. Int J Clin Lab Res 1992;22:196-200.

27. Erickson LA, Jin L, Wollan PC, Thompson GB, van Heerden J, Lloyd RV. Expression of p27kip1 and Ki-67 in benign and malignant thyroid tumors. Mod Pathol 1998;11:169-74.

28. Schipper DL, Wagenmans MJ, Peters WH, Wagener DJ. Significance of cell proliferation measurement in gastric cancer. Eur J Cancer 1998;34:781-90. 
29. Hsu DW, Hakim F, Biller BM, de la Monte S, Zervas NT, Klibanski A, et al. Significance of proliferating cell nuclear antigen index in predicting pituitary adenoma recurrence. J Neurosurg 1993;78:753-61.

30. Lloyd R, V. Molecular pathology of pituitary adenomas. J Neurooncol 2001;54:111-9.

31. Duchrow M, Gerdes J, Schluter C. The proliferationassociated Ki-67 protein: definition in molecular terms. Cell Prolif 1994;27:235-42.

32. Heck MM, Hittelman WN, Earnshaw WC. Differential expression of DNA topoisomerases I and II during the eukaryotic cell cycle. Proc Natl Acad Sci U S A 1988;85:108690.

33. Tanoguchi K, Sasano H, Yabuki N, Kikuchi A, Ito K, Sato S, et al. Immunohistochemical and two-parameter flow cytometric studies of DNA topoisomerase II alpha in human epithelial ovarian carcinoma and germ cell tumor. Mod Pathol 1998;11:186-93.
34. Takano H, Kohno K, Ono M, Uchida Y, Kuwano M. Increased phosphorylation of DNA topoisomerase II in etoposideresistant mutants of human cancer KB cells. Cancer Res 1991;51:3951-7.

35. Young WF Jr, Scheithauer BW, Kovacs KT, Horvath E, Davis $\mathrm{DH}$, Randall RV. Gonadotroph adenoma of the pituitary gland: a clinicopathologic analysis of 100 cases. Mayo Clin Proc 1996;71:649-56.

36. Turner HE, Nagy Z, Gatter KC, Esiri MM, Wass JA, Harris AL. Proliferation, bcl-2 expression and angiogenesis in pituitary adenomas: relationship to tumour behaviour. Br J Cancer 2000;82:1441-5.

37. Coire CL, Horvath E, Kovacs K, Smyth HS, Ezzat S. Cushing's syndrome from ectopic pituitary adenoma with peliosis: a histological, immunohistochemical, and ultrastructural study and review of the literature. Endocr Pathol 1997;8:65-74.

38. Hande KR. Etoposide: four decades of development of a topoisomerase II inhibitor. Eur J Cancer 1998;34:1514-21. 